\title{
Maize and precolonial Africa
}

\author{
Jevan Cherniwchan $^{\mathrm{a},{ }^{*}, \text { Juan Moreno-Cruz }}{ }^{\mathrm{b}, \mathrm{c}}$ \\ a Alberta School of Business, University of Alberta, 3-23 Business Building, Edmonton, Alberta, T6G 2R6, Canada \\ ${ }^{\mathrm{b}}$ School of Environment, Enterprise and Development, University of Waterloo, Environment 3 Building, 200 University Avenue West, Waterloo, Ontario, N2L \\ 3G1, Canada \\ c CESifo, Germany
}

\section{A R T I C L E I N F O}

\section{JEL codes:}

N57

O13

Q1

Keywords:

Africa

Columbian exchange

Maize

Slave trades

\begin{abstract}
A B S T R A C T
Columbus's arrival in the New World triggered an unprecedented movement of people and crops across the Atlantic Ocean. We study a largely overlooked part of this Columbian Exchange: the effects of New World crops in Africa. Specifically, we test the hypothesis that the introduction of maize increased population density and slave exports in precolonial Africa. We find robust empirical support for these predictions. We also find little evidence to suggest maize increased economic growth or reduced conflict. Our results suggest that rather than stimulating development, the introduction of maize simply increased the supply of slaves during the slave trades.
\end{abstract}

\section{Introduction}

Christopher Columbus's voyage in 1492 precipitated an unprecedented exchange between the Old and New Worlds. Among other things, this so-called "Columbian Exchange" led to the movement of both peoples and crops across the Atlantic Ocean. ${ }^{1}$ While most of this movement took place between Europe and the Americas, it is clear that Africa was also affected in profound ways. Over ten million people were forcibly taken from Africa to the New World as slaves between the sixteenth and nineteenth centuries during an episode that has had lasting effects on African societies. ${ }^{2}$ Yet, little is known about how other aspects of the exchange have shaped Africa and its history.

In this paper, we examine the effects of crop movements during the Columbian Exchange on precolonial Africa. ${ }^{3}$ Our examination is motivated by observations made by the historians Alfred Crosby and Philip Curtin that suggest the introduction of new crops from the Americas created an agricultural productivity shock that changed the dynamics of both populations and slavery in Africa. In his classic book, The Columbian Exchange: Biological and Cultural Consequences of 1492,
Crosby discusses the potential effects of these crops, writing:

"...we might hypothesize that the increased food production enabled the slave trade to go on as long as it did... The Atlantic slave traders drew many, perhaps most, of their cargoes from the rain forest areas, precisely those areas where American crops enabled heavier settlement than ever before." (Crosby, 1972, p. 188).

A variant of this statement is put forth by Curtin in The Atlantic Slave Trade: A Census:

“... at least two New-World crops were introduced into Africa by the sixteenth century: manioc and maize spread very widely and came to be two of the most important sources of food on that continent. If other factors affecting population size had remained constant, the predictable result would have been population growth wherever these crops replace less efficient cultigens... It seems possible and even probable that population growth resulting from new food crops exceeded population losses through the slave trade." (Curtin, 1969, p. 270, p. 270)

\footnotetext{
* Corresponding author.

E-mail addresses: jevan@ualberta.ca (J. Cherniwchan), juan.moreno-cruz@uwaterloo.ca (J. Moreno-Cruz).

${ }^{1}$ See Nunn and Qian (2010) for a brief overview of the Columbian Exchange. A detailed account is given in Crosby (1972).

${ }^{2}$ See, for example, the work of Nunn (2008), Nunn and Wantchekon (2011), Dalton and Leung (2014), Bertocchi (2016), Bertocchi and Dimico (2017) and Gershman (2017).

${ }^{3}$ For a recent overview of the literature examining the effects of crop movements during the Columbian Exchange, see Nunn (2014).

https://doi.org/10.1016/j.jdeveco.2018.10.008

Received 28 March 2018; Received in revised form 5 October 2018; Accepted 27 October 2018

Available online 30 October 2018

0304-3878/@ 2018 The Authors. Published by Elsevier B.V. This is an open access article under the CC BY-NC-ND license (http://creativecommons.org/licenses/ by-nc-nd/4.0/).
} 
Together, these observations suggest that the introduction of New World crops had a material effect on Africa by increasing both i) population density and ii) slave exports during the precolonial era. We test this two-part conjecture, which we term the Crosby-Curtin Hypothesis, and examine how the resulting changes shaped precolonial Africa.

While the population effects of maize envisioned by Crosby and Curtin follow directly from the Malthusian forces present in Africa during the Columbian Exchange, the link to slavery is less obvious. As such, the first step in our analysis is to develop a simple theoretical framework to illustrate how these same Malthusian forces may have also increased slave exports. Our starting point for this exercise is the Malthusian growth model featuring endogenous slavery developed by Lagerlof (2009). This model is well suited for our purposes; as highlighted by Fenske (2013), the Lagerlof (2009) model matches several key stylized facts about African societies during the Columbian Exchange. In the original Lagerlof framework, ruling political elites choose property rights for land and labor to maximize their payoff, and the incentive to enslave people to work in agriculture is increasing in the productivity of land. We adapt this framework to allow for the possibility that the elites sell slaves to foreign markets. This alters the effects of an increase in agricultural productivity; while the elite's incentive to keep slaves to work in domestic agriculture increases, decreasing returns to agriculture mean that the relative return to exporting slaves also increases. Thus, an agricultural productivity shock, such as that created by the introduction of New World Crops, will increase both the population density of and slave exports from an affected country.

The second step in our analysis is to test the predictions of the Crosby-Curtin Hypothesis empirically. We start by examining which New World crops, if any, could have created the change in agricultural productivity envisioned by Crosby and Curtin. Such a crop needs to satisfy three conditions. First, it must have had enough calories and nutrients to function as a primary dietary source. Second, it must have had a higher yield than existing African staples, so its adoption would have resulted in an increase in agricultural productivity. Finally, it must have been introduced and widely adopted in Africa in the midst of the slave trades.

Many New World crops were introduced into Africa following Columbus's discovery of the Americas, but only maize (Zea mays) satisfies these three conditions. Maize first arrived on the African coast during the seventeenth century. It was initially introduced by the Portuguese to supply their trading forts, but the crop was quickly adopted by African farmers due to its high energy yield, its low labor requirements, and its short growing season. Cultivation spread quickly; as we discuss below, the available historical evidence indicates that maize was grown across much of the African continent by the early 1700s. Given its characteristics and the timing of its introduction, maize is the most likely cause of any agricultural productivity shock. Hence, we focus our attention on maize.

While maize is the most likely source of an agricultural productivity shock, we do not observe the specific dates it was adopted due to the incomplete historical record. To address this challenge we exploit cross-country differences in geographic characteristics and the timing of the crop's introduction into Africa to identify the effects of maize. ${ }^{4}$ Our approach relies on the fact that while maize diffused rapidly across the African continent after its introduction in the mid-seventeenth century, it could not be grown everywhere due to differences in time invariant geo-climatic conditions. This means that only the subset of countries that were suitable for the cultivation of maize could have been affected (or "treated") by the crop when it was introduced into Africa. Hence, testing the Crosby-Curtin Hypothesis amounts to identifying the effects of maize on this group of countries. To do so, we adopt a variant of a

${ }^{4}$ Nunn and Qian (2011) use a similar approach to identify the effects of the introduction of the potato on population levels and urbanization rates in the Old World. simple difference-in-difference research design that compares outcomes from countries with large amounts of maize-suitable land to outcomes from countries with small amounts of maize-suitable land, before and after maize was introduced into Africa. This approach allows us to control for time-invariant country characteristics, such as geography, as well as continent-wide trends such as ongoing technological change and changes in the global demand for slaves, that would otherwise confound identification. We implement this design using a country-level panel data set that contains information on population levels between 1000 and 1900, slave exports between 1400 and 1800, the suitability of maize as a crop, and several other country characteristics.

We find robust evidence in support of both parts of the CrosbyCurtin Hypothesis. Specifically, we find that African countries that were suitable for the cultivation of maize experienced larger increases in both population density and slave exports after the crop was first introduced into Africa. The estimates from our preferred specifications, which include controls for differential trends in European contact and climate, suggest that following the introduction of maize, a $1 \%$ increase in maize-suitable land is associated with a $0.025 \%$ increase in population density and a $0.024 \%$ increase in slave exports. ${ }^{5}$ These estimates imply that the introduction of maize during the Colombian Exchange played a significant role in shaping precolonial Africa; for the average country, nearly $22 \%$ of the population growth over the period $1600-1900$, and $6 \%$ of the increase in slave exports at the height of the slave trades can be attributed to the introduction of maize.

The third, and final, step in our analysis is to ask whether the introduction of maize had effects on African societies beyond those envisioned by Crosby and Curtin. Our motivation for doing so stems from recent research that has shown that the introduction of New World crops during the Colombian Exchange (particularly, the white potato and sweet potato) increased economic growth (Nunn and Qian, 2011) and reduced conflict (Jia, 2014; Iyigun et al., 2015) in the Old World. In light of the evidence presented by Nunn (2008) and Nunn and Wantchekon (2011) indicating the slave trades negatively affected development in much of Africa, it is possible that the deleterious effects of increased slavery brought about by the introduction of maize may have been at least partially offset by the crop's effects on both growth and conflict. Using the same difference-in-difference strategy described above, we find little evidence that the introduction of maize increased economic growth or reduced conflict in Africa. Indeed, our estimates suggest that if anything, the introduction of maize may have increased conflict by increasing slavery.

Altogether, our estimates suggest that the introduction of maize during the Columbian Exchange played a significant role in shaping Africa's history by affecting population levels, slave exports and conflict. Affected African countries, however, were unable to utilize maize to escape the Malthusian trap.

Our work contributes to several strands of the literature. Our results make two main contributions to the recent literature examining the effects of the Columbian Exchange. First, we add to the literature studying the effects of the exchange in Africa. To date, the majority of this work has focused on the long-run effects of the slave trades (eg. Nunn (2008); Nunn and Wantchekon (2011)). We contribute to this line of research by examining how another aspect of the exchange, the introduction of maize, affected outcomes in precolonial Africa.

Second, we contribute to the body of work examining the effects of agricultural productivity shocks created by the introduction of New Word crops in the Old World. Some of this research, particularly the study of the effects of the white potato by Nunn and Qian (2011), finds

\footnotetext{
5 These findings are robust to controlling for a number of other factors that have been identified as affecting either population levels of slavery, including disease environment, terrain ruggedness, and distances to the nearest slave markets, our measure of maize suitability, and the effects of other New World crops.
} 
that the introduction of New World crops stimulated economic growth in affected parts of the Old World. In contrast, our results suggest that maize failed to lead to economic growth in Africa. This finding aligns with recent work by Chen and Kung (2016) who find that the introduction of maize failed to increase economic growth in China. Hence, our results provide further evidence that agricultural productivity shocks alone are not sufficient for generating economic growth.

Our results also contribute to the literature studying precolonial Africa. Much of this research has focused on precolonial institutions, in part because they have been shown to be an important determinant of development in Africa today (e.g. Gennaioli and Rainer (2007); Michalopoulos and Papaioannou (2013)). We contribute to this literature by highlighting an event that likely shaped these institutions; given that land abundance and slavery were key determinants of precolonial institutions in Africa (Fenske, 2013), our results suggest that by introducing maize, Europeans affected Africa's institutions prior to the colonial period.

We also add to a large literature examining the determinants of the slave trades. At present, this literature has largely focused on factors that affected the demand for slaves (e.g. Eltis et al. (2005)) or the cost of transporting slaves (e.g. Dalton and Leung (2015); Eltis et al. (2010)). However, some recent research has begun to examine the supply side determinants of the slave trades, such as the ruggedness of terrain (Nunn and Puga, 2012), climate shocks (Fenske and Kala, 2015; Boxell, 2018), the managerial quality of ship captains (Dalton and Leung, 2016), and the guns-for-slave cycle (Whatley, 2018). We contribute to this literature by demonstrating how the agricultural productivity shock created by the introduction of maize increased the supply of slaves from Africa during the slave trades. ${ }^{6}$

Finally, our work also contributes to a burgeoning literature studying the determinants of conflict in precolonial Africa. In recent work, Fenske and Kala (2017) show that the suppression of the West African slave trades in 1807 increased conflict elsewhere on the African continent. Our paper is more closely related to that of Boxell (2018) who shows that droughts increased slave exports by increasing conflict. To help explain his empirical results, Boxell builds a model based on Fenske and Kala (2015) to highlight how drought induced decreases in agricultural productivity can increase slave exports by affecting the opportunity cost of participating in the slave trades. Our findings complement this work by showing that conflict may have also increased as a result of increases in agricultural productivity; our results suggest that the introduction of maize increased both the likelihood and number of conflicts primarily by increasing the magnitude of the slave trades.

The remainder of this paper proceeds as follows. Section 2 describes our simple Malthusian framework that links changes in agricultural productivity to changes in populations and slave exports. Section 3 provides a background of the key New World crops that were introduced into Africa during the Columbian Exchange, highlights why maize is the most likely source of an agricultural productivity shock, and describes our strategy for identifying the effects of maize, our data, and the specification we use in our empirical analysis. Section 4 presents our empir-

\footnotetext{
${ }^{6}$ Our work is also related to that of Rönnbäck and Theodoridis (2018) who present a case study examining another hypothesis that links agricultural productivity to the slave trades. This hypothesis, first put forth by Hopkins (1973), suggests that the slave trades were driven in part by the relatively low level of agricultural productivity in Africa when compared to the Americas. Using archival data from European colonies, Rönnbäck and Theodoridis present evidence that Senegambia had lower agricultural productivity levels than the Americas during the 19th century, and interpret this evidence as support for the low-productivity hypothesis. Although the evidence provided by Rönnbäck and Theodoridis is not a causal test, it is important to note that our findings are not inconsistent with the low-productivity hypothesis even if it is true. Our results suggest that even if the resulting level of agricultural productivity was relatively low when compared to the Americas, the increase in productivity induced by the introduction in maize increased slave exports.
}

ical findings. Section 5 concludes.

\section{Malthus in Africa: agricultural productivity, population, and the slave trades}

As we noted above, our analysis centers on what we term the CrosbyCurtin Hypothesis: the hypothesis that increases in agricultural productivity created by the introduction of New World crops increased both i) population density in, and ii) slave exports from affected parts of Africa. While neither Crosby (1972) nor Curtin (1969) explicitly described the effects of agricultural productivity changes in these terms, both parts of this hypothesis can be understood through a Malthusian lens.

Part one of the hypothesis links the introduction of New World crops with increased population density in Africa. This linkage is relatively straightforward. At the time New World crops were introduced, Africa was governed by a Malthusian regime, with per-capita incomes at subsistence levels (see, for example, Clark (2007) and Ashraf and Galor (2011)). This means that equilibrium income levels were unaffected by the productivity of land. Any income in excess of the subsistence level, such as that created by an agricultural productivity shock, was translated into an increase in population levels, necessarily increasing population density. Hence, if the hypothesis is true, we should observe significant changes in population density in the parts of Africa that were affected by the introduction of maize.

Part two of the Crosby-Curtin hypothesis ties the introduction of New World crops to increased slave exports. We can illustrate this relationship with the aid of the model developed by Lagerlof (2009) to examine slavery in Malthusian societies. As discussed by Fenske (2013), this model matches several key stylized facts about African societies and their institutions during the precolonial era, making it well suited for our setting.

Lagerlof presents a Malthusian growth model featuring overlapping generations in which property rights over land and labor are endogenously determined by the choices of political elites. For our purposes, the model's key prediction is that, in a society with slavery, the incentive to enslave people is increasing in the productivity of land. Lagerlof's model, however, does not allow for the export of slaves. As such, we develop a variant of the model that allows for this, and highlight a potential channel via which agricultural productivity shocks may affect slave exports. ${ }^{7}$

We assume societies are governed by a ruling political elite that exhibits property rights over land and labor. ${ }^{8}$ As such, the elite enslaves their population and chooses whether to employ slaves in agriculture

\footnotetext{
7 While we utilize our theoretical framework to highlight the possible effects of changes in agricultural productivity on slave exports, maize may have also affected slave exports via other channels. For example, maize may have also affected slave exports by directly reducing transportation costs. The introduction of maize may have affected these costs in two ways. First, it may have lowered transport costs directly by providing a cheaper foodstuff for feeding slaves while they were being transported; maize had a number of advantageous qualities that made it particularly well suited for transport (McCann, 2005). Second, it may have indirectly reduced transport costs by decreasing mortality rates for slaves during transport. A key determinant of total slave exports, particularly from the interior of the African continent, was the mortality rate (Vansina, 1990; Lovejoy, 2000). Hence, a cheap, easily transportable food such as maize may have increased the number of slaves exported during the slave trades by reducing the number of deaths due to malnourishment.

${ }^{8}$ In the Lagerlof (2009) model the economy potentially transitions from an egalitarian regime, to a despotic regime where society is ruled by an elite that maintains slaves and holds all land, to a society featuring free labor. We focus on the second case; we are not interested in modelling the transition between these states given the pervasiveness of slavery in Africa during the Columbian Exchange.
} 
or to sell them to foreign markets. ${ }^{9}$ As in Lagerlof (2009), the elite is infinitely lived, and non-elite agents (slaves) live for two periods. ${ }^{10}$ For convenience, we normalize the size of the elite to one. Furthermore, the agricultural productivity of land is a function of the current set of crops available for cultivation.

Time is discrete. In each period $t$, the elite chooses the number of slaves to employ in agriculture and the number of slaves to sell to foreign markets to maximize their payoff, which is given by:

$\pi_{t}=\max _{S_{t}, X_{t}}\left\{F\left(A_{t}, S_{t}\right)-\bar{c} S_{t}+v_{t} X_{t} \mid S_{t}+X_{t} \leq P_{t}\right\}$

where $F\left(A_{t}, S_{t}\right)=A_{t}^{\alpha} S_{t}^{1-\alpha}$ is agricultural output, $A_{t}$ denotes agricultural productivity, $S_{t}$ denotes the population of domestic slaves used in agriculture, $X_{t}$ denotes the population of slaves exported to foreign markets, and $P_{t}$ denotes the size of the society's population at time $t .{ }^{11}$ Slaves are each paid the minimal amount required for a subsistence level of consumption, $\bar{c} .{ }^{12}$ If slaves are exported, elites receive an exogenous price of $v_{t} \cdot{ }^{13}$ For convenience, we let the agricultural good be the numeraire, so that $v_{t}$ is measured in units of agricultural goods. The total payoff, $\pi_{t}$, measured in terms of agricultural output, is used by elites for their own consumption and for raising their children.

Solving equation (1) yields the size of the domestic slave population:

$S_{t}^{*}=\left[\frac{1-\alpha}{\bar{c}+v_{t}}\right]^{\frac{1}{\alpha}} A_{t}$

and the number of exported slaves $X_{t}^{*}=P_{t}-S_{t}^{*} \cdot{ }^{14}$ The elite's payoff is then given by:

$\pi_{t}^{*}=\alpha\left[\frac{1-\alpha}{\bar{c}+v_{t}}\right]^{\frac{1-\alpha}{\alpha}} A_{t}+v_{t} P_{t}$

As in Lagerlof (2009), population growth is determined by the choices of elites. Slaves do not have children; because they are paid at subsistence levels, slaves cannot allocate any resources to offspring. In contrast, elites make consumption and reproductive choices to maximize their utility:

$u\left(c_{t}, n_{t}\right)=\ln c_{t}+\rho \ln n_{t}$

where $c_{t}$ is consumption and $n_{t}$ is the number of the elite member's children. Elites maximize their utility subject to the budget constraint $\pi_{t}=c_{t}+q n_{t}$, where $q$ is the consumption cost of raising a child, measured in units of agricultural output, and $\pi_{t}$ is the payoff derived from agricultural output and from selling slaves. It follows from the elite's maximization problem that the optimal number of children is $n_{t}=\frac{\rho}{q} \pi_{t}$.

\footnotetext{
${ }^{9}$ Given our focus on understanding how agricultural productivity shocks affected the supply of slaves, we consider a small open economy in which foreign demand is exogenously given.

${ }^{10}$ It is worth noting that, unlike Lagerlof (2009), we do not distinguish between "internal" and "external" elites. Lagerlof makes this distinction for analytic convenience given that he is interested in understanding transitions between property rights regimes; focusing on a single unified elite has no effect on the main results (Lagerlof, 2008). Given our focus on a regime with slavery, here we focus on a single ruling elite that should be thought of as a domestic ruling class.

11 This formulation contains an implicit assumption that there are diminishing returns to agriculture. This is a common assumption in Malthusian models (e.g. Ashraf and Galor (2011)).

12 We could allow for variable guarding costs, as in Lagerlof (2009), by assuming that each slave requires $\gamma$ guards who are paid the subsistence level of income, so that the costs of maintaining slaves are equal to $(\bar{c}+\gamma)$. Doing so does not affect our results.

13 The underlying assumption is that there are many elites providing slaves to the export market, thus making them price-takers in the export market, as in Gillezeau and Whatley (2011).

14 The assumption here is that $P_{t}$ is large enough so that $X_{t}>0$. Otherwise, $S_{t}=P_{t}$ and the analysis proceeds as in Lagerlof (2009).
}

The population in period $t+1$ is then equal to the number of children at time $t$; that is:

$P_{t+1}=\frac{\rho}{q}\left[\alpha\left[\frac{1-\alpha}{\bar{c}+v_{t}}\right]^{\frac{1-\alpha}{\alpha}} A_{t}\right]+\frac{\rho v_{t}}{q} P_{t}$

The dynamics of the model are straightforward. The population growth equation is a straight line in $\left\{P_{t}, P_{t+1}\right\}$ space with a slope given by $\rho v_{t} / q$. We assume that the return to export slavery is not too high relative to the return to agricultural production; that is $q / \rho>v_{t}$. This ensures that consumption cannot be maximized solely through the sale of slaves on export markets. To see this, note that $c_{t} / n_{t}=q / \rho$ from the elite's utility maximization problem. This means that $c_{t}>v_{t} n_{t}$; that is, the payoff from selling all children as slaves is less than the value of consumption obtained when some slaves are employed in agriculture. Under the assumption that $q / \rho>v_{t}$, the system evolves monotonically towards the unique and interior steady state. This also implies that for all times, population sizes along the transition path under increased land productivity is always higher than the low productivity path.

The steady state is given by:

$\bar{P}=\left[\frac{\rho \alpha}{q-v \rho}\right]\left[\frac{1-\alpha}{\bar{c}+v}\right]^{\frac{1-\alpha}{\alpha}} A$

$\bar{S}=\left[\frac{1-\alpha}{\bar{c}+v}\right]^{\frac{1}{\alpha}} A$

$\bar{X}=\left[\frac{\rho \alpha}{q-v \rho}-\frac{1-\alpha}{\bar{c}+v}\right]\left[\frac{1-\alpha}{\bar{c}+v}\right]^{\frac{1-\alpha}{\alpha}} A$

where $\bar{P}, \bar{S}$ and $\bar{X}$ denote the steady state levels of population, domestic slavery and slave exports, respectively. Given our interest in understanding how agricultural productivity shocks affected societies with positive levels of domestic slavery and slave exports, we assume $X(t)>0$. This requires that the benefit of selling slaves in the international market $(\bar{c}+v)$ is greater than the cost measured in terms of a reduction in agricultural output $\left(\frac{1-\alpha}{\alpha} \frac{q-v \rho}{\rho}\right)$.

Having solved for the economy's steady state, we are now able to formalize the effects of an agricultural productivity shock such as that created by the introduction of maize:

Crosby-Curtin Hypothesis. If the relative returns of export slavery to agricultural production are not too high and the benefit of selling slaves in the international market is greater than the cost measured in terms of a reduction in agricultural output, then an increase in the productivity of agriculture:

(i) increases population levels, and

(ii) increases the number of domestic slaves and the number of slaves that are exported.

Proof. Both (i) and (ii) follow from taking derivatives of equations (6)-(8) with respect to $A$.

This proposition shows that the Crosby-Curtin Hypothesis can be rationalized with the aid of a Malthusian framework. Part (i) of the proposition states that, as in Malthusian models in which there is no slavery (such as Ashraf and Galor (2011)), an agricultural productivity shock can increase population levels, leading to an increase in population density. This means that if the hypothesis is true, we should observe an increase in population density following the introduction of maize into Africa. Part (ii) of the proposition indicates that an agricultural productivity shock increases the benefit of holding domestic slaves, leading to an increase in the domestic slave population. However, not all people are allocated to agriculture; decreasing returns to agriculture ensure that the relative return to slave exports increases, 
Table 1

Nutrient contents of various staple crops.

\begin{tabular}{lllllll}
\hline Crop & \multicolumn{2}{l}{ Nutrients per $100 \mathrm{~g}$} & & & \\
\cline { 2 - 6 } & Water $(\mathrm{g})$ & Energy $(\mathrm{kcal})$ & Protein $(\mathrm{g})$ & Fat $(\mathrm{g})$ & Carbohydrates $(\mathrm{g})$ & Fibre $(\mathrm{g})$ \\
\hline Sorghum & 12.40 & 329 & 10.62 & 3.46 & 72.09 & 6.7 \\
Millet & 8.67 & 378 & 11.02 & 4.22 & 72.85 & 8.5 \\
Maize & 10.37 & 365 & 9.42 & 4.74 & 74.26 & 7.3 \\
Cassava & 59.68 & 160 & 1.36 & 0.28 & 38.06 & 1.8 \\
Sweet Potato & 77.28 & 86 & 1.57 & 0.05 & 20.12 & 3.0 \\
White Potato & 79.34 & 77 & 2.02 & 0.09 & 17.47 & 2.2 \\
\hline
\end{tabular}

Notes: Data taken from the USDA National Nutrient Database for Standard Reference 26 Software v.1.3.1. http://ndb. nal.usda.gov.

meaning that a larger fraction of slaves are sold to foreign markets. ${ }^{15}$ As such, for a given area of land, we should also observe an increase in slave exports following the introduction of maize. In what follows, we test the two parts of this hypothesis empirically.

\section{Empirical research design}

\subsection{A digression on maize}

Several New World crops, including capsicum peppers, cassava, maize, peanuts, white potatoes, sweet potatoes, and tomatoes, were introduced into Africa following Columbus's arrival in the Americas in 1492. Testing the Crosby-Curtin hypothesis requires determining which crops, if any, were capable of creating the change in agricultural productivity necessary to change population levels and slave exports during the slave trade.

We make this determination on the basis of three conditions. First, such a crop must be a staple with enough calories and nutrients to function as a primary dietary source. If it does not, it is unlikely that the adoption of the crop would result in the change in nutrition required to affect populations or slavery. Second, the crop must be more productive than indigenous African staples, so that adoption results in an increase in agricultural productivity. Finally, the crop must have been introduced and widely adopted across the African continent during the course of the African slave trade.

While several new plants were introduced into Africa as part of the Columbian Exchange, only a few had the calories and nutrients required for use as a staple crop. These crops are listed in Table 1, which reports the nutritional content of various African staples using data from the United States Department of Agriculture. ${ }^{16}$ Four of these plants (maize, cassava, sweet potatoes and white potatoes) originate in the New World. The remaining two crops (sorghum, and millet) are indigenous to Africa and were the main cereal crops before the Columbian Exchange (McCann, 2005). Table 1 indicates that sorghum and millet have substantially more calories, protein, fat and fibre than all but one of the New World crops. Only maize has a similar nutrient content. This means that in terms of nutrition, New World plants were largely poor substitutes for indigenous crops. As such, any change in agricultural productivity arising from the introduction of new staples must have been a product of a change in the physical productivity of agriculture.

There is substantial variability in the agricultural productivity of staple crops within Africa. This can be seen in Table 2, which reports the earliest available estimates of average annual crop yields in Africa

\footnotetext{
15 While our model assumes the returns to export are constant at global prices $v_{t}$, the results would also hold with diminishing returns to exports provided that the marginal returns to export slavery diminish at a lower rate than those of agricultural productivity.

16 The table reports the nutrient value by weight to ensure the direct comparability of the nutrients available from consuming the same quantity of various crops.
}

Table 2

Annual crop yields of various staple crops.

\begin{tabular}{lll}
\hline Crop & Yield (kg/ha) & Energy MJ/ha \\
\hline Millet-Sorghum & 1200 & 17,800 \\
Maize & 1700 & 26,000 \\
Cassava & 4000 & 26,800 \\
Sweet Potatoes & 8000 & 28,800 \\
White Potatoes & 4400 & 14,200 \\
\hline Notes: With the exception of white potatoes, annual \\
yield data based on Miracle (1966), Table 11-1, p. 207. \\
Annual yield for white potatoes taken from Nunn and \\
Qian (2011). Energy yields calculated using data from \\
Table 1.
\end{tabular}

in terms of both physical output and energy content. These estimates are based on data reported in Miracle (1966), Nunn and Qian (2011) and Table 1 . As the first column of the table shows, maize, cassava, and sweet and white potatoes all have a higher physical yield than millet and sorghum. This suggests that the adoption of any new crops would have increased raw agricultural output from existing farmland. There are also important differences in physical characteristics (such as water and carbohydrate content) across plants that could affect adoption. This is accounted for in the second column of Table 2, which displays the energy value corresponding to the yield listed in the first column. This column shows that maize, cassava and sweet potatoes all yield more energy per hectare than millet and sorghum. This means each of these crops could have functioned as a substitute for millet and sorghum.

This, however, ignores the significant differences in the quantity of labor required to grow and harvest each plant. Of the staple crops in Africa, maize has the lowest labor requirements (Purseglove, 1972; Hogendorn and Gemery, 1990-1991; McCann, 2001), particularly after processing, storage and transport are taken into account (Miracle, 1966). Given that a hectare of maize has a similar energy content to a hectare of cassava or sweet potatoes, this suggests that maize was the most productive of the New World crops introduced into Africa, and had the greatest potential to create an agricultural productivity shock.

Maize has several other characteristics not found in other New World plants that would have made it an attractive substitute to indigenous crops for African farmers. As noted by the botanist J.W. Purseglove, "...it provides nutrients in a compact form; it is easily transportable; the husks give protection against birds and rain, it stores well if properly dried; [and] it can be harvested over a long period, first as immature cobs, and can be left standing in the field at maturity before harvesting" (Purseglove, 1972, p. 301). Moreover, maize was grown in a manner similar to sorghum and millet, making adoption relatively straightforward. Agricultural economist William Jones indicates that, "To grow [maize], the African farmer had only to acquire the seed; all the rest of the process was familiar" (Jones, 1959, p. 74). Maize also grew where crops were not previously planted, increasing the quantity of agricultural land, and could be harvested multiple times during a single growing season, providing a source of food while other crops were still growing (McCann, 2001). 
While sparse, the available evidence on the timing of maize's introduction into Africa also suggests that it is the most likely source of an agricultural productivity shock. It is believed maize was first brought to West Africa by the Portuguese, although the exact date of introduction is not known due to the limited historical record (Miracle, 1966). ${ }^{17}$ Initially, it was introduced to the islands of Cape Verde and Sao Tomé; the observations of European navigators suggest the crop was present on both islands by the mid 16th century (McCann, 2005). The observations of European travellers also suggest that maize travelled from these islands to the Gold Coast sometime during the 17th century (McCann, 2005), but exactly when or why maize travelled to the continent is unknown. Evidence of how maize spread inland is also sparse. However, while there is little evidence from European records on the inland diffusion of maize at this time (Miracle, 1966), recent archaeological research suggests that maize diffused rapidly inland from the coast; there is evidence of maize cultivation over $500 \mathrm{~km}$ (300 miles) from the coast of Ghana by 1700 (Stahl, 1999). Indeed, it is thought that maize had replaced millet and sorghum to become the main crop in West Africa by the start of 18th century (Juhé-Beaulaton, 1990). ${ }^{18}$

The timing of the arrival of maize in other parts of Africa is also not well known. Maize appears to have arrived in West-Central Africa during the early part of the 17th century; there is evidence of maize in the Congo Basin and Angola around this time, however it appears that it was not a primary crop until the latter third of the century (Miracle, 1966). There is also some evidence that maize was cultivated as a crop in East Africa during this period. The limited historical evidence indicates that maize had arrived in Tanzania by 1668, Madagascar by 1717 and Mozambique by 1750 (Miracle, 1966). Recent archaeological evidence (Lamb et al., 2003; Kusimba, 2004) suggests that maize was also present in interior Kenya at this time.

Altogether, the available evidence suggests that maize had diffused across the African continent by the middle of the slave trades. This is in stark contrast to the other New World crops with high yields. While sweet potatoes were introduced into Africa by the Portuguese around the same time as maize (Alpern, 1992), the crop did not spread until the 19th century due to British influences (O'Brien, 1972). The Portuguese also brought cassava to Africa, but did so after the introduction of maize (Alpern, 1992). Cassava was not widely adopted until the 19th century, in part because it contains dangerous amounts of hydrogen cyanide; thus, widespread adoption required learning how to process the crop to avoid poisoning (Jones, 1959). ${ }^{19}$ The white potato also arrived later, towards the end of the nineteenth century (Nunn and Qian, 2011). As such, sweet potatoes, white potatoes, and cassava were adopted near the end of the slave trades.

In sum, the available evidence suggests that maize is the most likely cause of any agricultural productivity shock. Maize has similar nutrient levels to the indigenous staples millet and sorghum, but is much more productive as it has both a higher yield and lower labor requirements. Moreover, it is more productive than other New World staples and has several other advantageous characteristics. Finally, it was the only crop whose cultivation diffused widely during the slave trades. As such, we focus our analysis on the effects of maize. ${ }^{20}$

\footnotetext{
17 It has also been suggested that maize was introduced into West Africa by traders from Egypt who obtained maize from Spain (Miracle, 1965), however recent genetic research tracing the diffusion of maize has not been able to substantiate this hypothesis (Mir et al., 2013).

${ }^{18}$ It is worth noting that while maize is thought to have become the main crop by the beginning of the 18th century, there is little-to-no evidence of the relative magnitudes of each crop's production across Africa at this time.

19 As noted by Crosby (1972), with the exception of the Congo, cassava was not a staple crop in any widespread area of Africa before 1850 .

${ }^{20}$ While maize is the main focus of our analysis, we also explore the effects of the introduction of cassava, sweet potatoes, and white potatoes in our empirical analysis below.
}

\subsection{Identifying the effects of maize in Africa}

Testing the Crosby-Curtin Hypothesis requires that we identify the effects of changes in agricultural productivity arising from the introduction of New World crops on both population density and slave exports in Africa. As we discussed above, these productivity changes were most likely caused by the introduction of maize, meaning that we must identify its effects on both outcomes. Doing so is complicated by the fact the historical record is incomplete and we do not observe the exact dates at which maize was adopted as a staple crop in different countries in Africa. To address this issue we follow the approach used by Nunn and Qian (2011) and exploit two sources of identifying variation: (i) crosscountry differences in the suitability of land for growing maize as a crop, and (ii) temporal variation in the availability of maize created by its introduction onto the African continent.

Our first source of identifying variation arises from the fact that maize could not be grown everywhere in Africa due to cross-country differences in time-invariant geo-climactic conditions. This can be seen from Fig. 1, which depicts data on the suitability of maize as a crop from the Food and Agriculture Organization of the United Nations (FAO)'s Global Agro-Ecological Zones (GAEZ) database. The GAEZ database provides $0.5^{\circ}$ by $0.5^{\circ}$ grid-cell measures of potential crop yield on the basis of geo-climatic constraints and different agricultural inputs. ${ }^{21}$ The figure illustrates maize suitability with low input intensity and rain-fed irrigation, reflecting the agricultural technology typically available in Africa during our period of study.

As shown in the figure, there is significant variation in the suitability of maize as a crop across Africa. The figure divides suitability into eight possible categories, from "Very High", in dark green, to "Not Suitable" in light grey. These categories reflect differences in the potential capac-

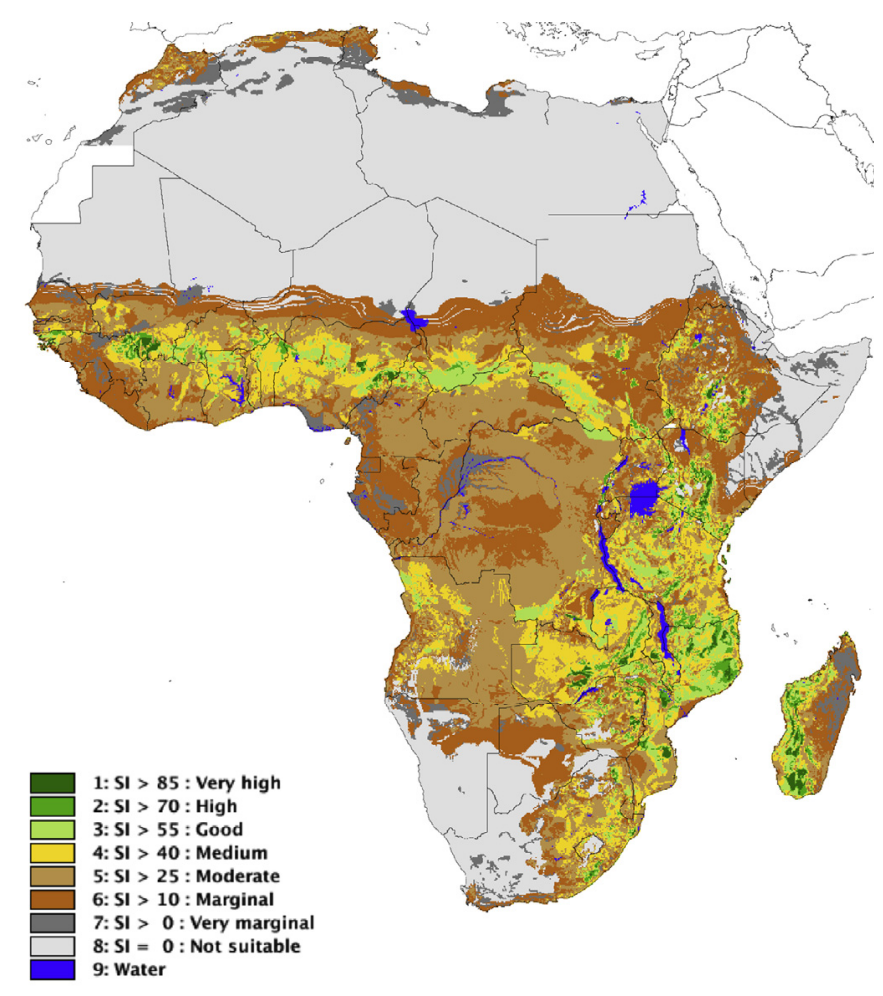

Source: GAEZ database (IIASA/FAO, 2012).

Fig. 1. The suitability of land for cultivating maize in Africa.

\footnotetext{
${ }^{21}$ For an overview of the FAO's GAEZ database, see Nunn and Qian (2011).
} 
ity of land to produce maize at the maximum yield due to differences in geographical, soil and climatic conditions. For example, very high suitability locations are able to produce at least $85 \%$ of their constrainedfree crop yields, while marginal suitability locations are able to produce at $10 \%$ of their benchmark. These differences create variation we can use to identify the effects of maize; we can compare average outcomes from places where it is highly suitable (such as parts of Nigeria or Madagascar) with average outcomes from locations where it is not (such as much of Namibia or Gabon).

Our second source of identifying variation arises from changes in the availability of maize in Africa over time. As we discussed above, maize is not indigenous to Africa; it was first introduced into the Gold Coast sometime in the seventeenth century, at which point it diffused rapidly across the continent. Given that we do not observe the exact timing or direction of this diffusion, we treat the introduction of maize as a shock common to all countries. This yields temporal variation we can exploit by comparing average outcomes before and after maize was introduced into Africa.

We identify the effects of the introduction of maize on both population density and slave exports by exploiting these two sources of variation using differences-in-differences. This approach compares either the average population densities of, or the average slave exports from, countries where land was suitable for adopting maize as a crop with the same outcome from countries where adoption was not possible due to an absence of suitable land. This means we are able to control for a number of time-invariant factors, such as a country's geographic characteristics and advantages, and trends common to all African countries, such as ongoing technological change, and changes in the global demand for slaves, that would otherwise confound identification.

This research design relies, in part, on the fact that maize was only suitable as a crop in a subset of countries. This means that, while it was potentially available everywhere in Africa after its introduction, maize could only be adopted in places where it could be grown due to exogenous geo-climatic factors. As such, while all countries may have tried to adopt maize once it was introduced due to factors such as existing population pressures, adoption was not possible everywhere due to geography. Given that the suitability of land for growing maize was not known before the crop was introduced, this rules out the possibility that our estimates are capturing the effects of factors such as existing population pressure rather than the effects of maize. ${ }^{22}$

In order to credibly identify the effects of maize, our research design also requires an assumption that there are no other country-specific factors related to the introduction of maize driving differences in outcomes across countries over time. Given that Africa experienced many significant changes around the time maize was introduced, we examine the veracity of this assumption in our analysis below.

\subsection{Data}

As discussed above, our research design requires cross-country data on the suitability of maize. We follow the approach taken by Nunn and Qian (2011) and construct this measure using the FAO-GAEZ data. In our main analysis, we define each parcel of land in the FAO-GAEZ data as suitable for maize if it is classified as having very high, high, good or medium suitability index under low-input productivity and rain

\footnotetext{
${ }^{22}$ While the fact that the maize suitability was unknown prior to the crop's introduction into Africa meaning that populations could not have sorted according to the suitability of land for growing maize, populations may have sorted according to the land's suitability for growing indigenous staple crops. This creates the potential that the population pressures at the time of maize's introduction actually reflect the suitability of maize as a crop if maize and indigenous crops are highly correlated. We examine this possibility further in our empirical analysis below.
}

irrigation conditions. ${ }^{23}$ These conditions reflect the agricultural technology available in Africa during our period of study. ${ }^{24}$ Based on this definition of suitability, any parcel of land that produces at least $40 \%$ of the benchmark capacity is assumed to be suitable for the production of maize. We then calculate the total area that is classified as suitable in each country. ${ }^{25}$

Our empirical analysis also requires data on population density and slave exports by country (both measured in persons per $\mathrm{km}^{2}$ ) before and after the introduction of maize. We create these variables using data from two main sources.

Our population data comes from Nunn and Qian (2011). These data are based on research by McEvedy and Jones (1978), and contain information on population levels for each country in Africa by century from 1000 to 1700 , and by half century from 1750 to 1900 . Some authors have expressed doubts about the accuracy of these data (e.g. Austin (2008) and Hopkins (2009)), meaning one of our dependent variables is potentially measured with error. However, any classical measurement error will not bias our estimates, and any systematic non-classical error will be captured by the country and year fixed effects that we include in our empirical specifications. ${ }^{26}$

We obtain data on Trans-Atlantic, Indian Ocean, Trans-Saharan and Red Sea slave exports from Nunn (2008). These data contain information on total number of slaves exported by country by century from the 1400 s to the end of the slave trades. ${ }^{27}$

Combining these three data sources yields the two main panel data sets that we utilize in our analysis. The first contains information on population density and maize suitability by country and by century for the period 1000-1700 and by half century for the period 1750-1900. The second contains information on slave exports (measured in persons exported per $\mathrm{km}^{2}$ ) and maize suitability by country and century for the period 1400-1800.

We supplement our main data sets with data from additional sources to account for other factors that may potentially confound our analysis. We construct measures of the suitability of other New World crops (cassava, white potatoes, and sweet potatoes), and the two primary indigenous African crops (pearl millet and sorghum) using the FAO-GAEZ

\footnotetext{
${ }^{23}$ We examine the robustness of our baseline results to this definition in the online appendix.

${ }^{24}$ As indicated by the GAEZ, "Under the low input, traditional management assumption, the farming system is largely subsistence based and not necessarily market oriented. Production is based on the use of traditional cultivars (if improved cultivars are used, they are treated in the same way as local cultivars), labor intensive techniques, and no application of nutrients, no use of chemicals for pest and disease control and minimum conservation measures." (IIASA/FAO, 2012).

25 One potential concern with our use of the FAO-GAEZ data is whether a modern measure of maize suitability captures historical conditions. In Figure A1 of the online appendix, we show that there is a strong correlation between our measure of maize suitability and both historical maize cultivation and historical maize production.

${ }^{26}$ We examine the issue of potential measurement error in our population data further in the online appendix.

27 The data from the Trans-Atlantic slave trade is reported for the periods 1450-1521, 1527-1599, 1600-1699, 1700-1799 and 1800-1866, while the data from the Indian Ocean slave trade is reported for the periods 1400-1599, 1600-1699, 1700-1799 and 1800-1899, and the data from the Trans-Saharan and Red Sea slave trades are reported for the periods 1400-1599, 1600-1699, 1700-1799 and 1800-1913. To match the data from the Indian Ocean, TransSaharan and Red Sea slave trades with the data from the Trans-Atlantic slave trade, we generate estimates of slave exports by century for the period 1400-1499 and 1500-1599 by equally apportioning the estimates from 1400 to 1499 across the two centuries. We then match the four data sets by treating the Trans-Atlantic slave trade estimates for $1450-1521$ as a measure of slave exports during the 1400 s, the estimates for $1527-1599$ as a measure of slave exports during the 1500 s.
} 
database. ${ }^{28}$ We obtain data on elevation and distance to equator from Nunn and Qian (2011). Measures of the stability of malaria transmission in each country are taken from Kiszewski et al. (2004). We construct the Tse-Tse fly suitability index for each country using the procedure developed in Alsan (2015). Data on each country's ruggedness, distance to coast, fraction of land within $100 \mathrm{~km}$ of an ice free coast, distance to the closest Trans-Atlantic, Indian Ocean, Trans-Saharan, and Red Sea slave market is taken from Nunn and Puga (2012). We also classify countries into regions following Nunn and Puga (2012). Summary statistics for each data set are presented in Table A1 of the online appendix.

\subsection{Empirical specification}

We implement our research design using the following empirical specification:

$y_{i t}=\beta\left[\right.$ Maize $_{i} \times$ Post $\left._{t}\right]+X_{i t} \Gamma+\eta_{i}+\lambda_{t}+\mu_{i t}$

where $y_{i t}$ is the outcome of interest (either $\ln$ (population/area), or $\ln \left(1+\right.$ slaveexports/area) in country $i$ at time $t^{29}$ Each country's treatment is captured by $\left[\right.$ Maize $_{i} \times$ Post $\left._{t}\right]$, which is the natural log of one plus the total area in country $i$ that is suitable for growing maize (the area "treated" by maize) interacted with a post-introduction indicator. ${ }^{30} \mathrm{We}$ assign the post-introduction indicator a value of 1 for the period 1600 onward, given that the available historical evidence suggests that the diffusion and adoption of maize began during the 1600 s. ${ }^{31} X_{i t}$ are additional controls that capture other factors that may have also affected the adoption of maize. $\eta_{i}$ is a country fixed effect that capture unobserved time-invariant factors such as soil quality and elevation that affect population or slave exports. $\lambda_{t}$ is a time period fixed effect that captures aggregate shocks common to all countries that would affect population or slave exports, such as ongoing technological progress or worldwide changes in the demand for slaves. $\mu_{i t}$ is an error term that captures idiosyncratic changes in either population density, or slave exports.

The coefficient of interest in equation (9) is $\beta$, which captures the effect of the introduction of maize on the outcome of interest. When population is the outcome of interest, the estimated coefficient $\hat{\beta}$ measures the change in population density in countries suitable for growing maize following its introduction into Africa relative to the change in population in countries that were not capable of growing maize. Similarly, when slave exports are the outcome of interest, $\widehat{\beta}$ measures the change in slave exports in countries suitable for growing maize following its introduction into Africa relative to the change in slave exports in countries that were not capable of growing maize. In each case, $\widehat{\beta}$ is identified from within-country comparisons over time. For the CrosbyCurtin hypothesis to hold, the introduction of maize must have a positive and significant effect on both population density and slave exports, meaning we should observe $\widehat{\beta}>0$ from both regressions.

\footnotetext{
${ }^{28}$ We construct these measures using the same procedure used for maize described in the main text.

${ }^{29}$ We adopt these transformations to address the skewness in each variable. We adopt the transformation $\ln (1+$ slaveexports/area) to be consistent with previous work (i.e. Nunn and Wantchekon (2011) or Nunn and Puga (2012)) given that some countries export zero slaves in a given century. In the online appendix, we examine the robustness of our main findings to instead adopting an inverse-hyperbolic sine transformation to address the skewness in slave exports.

${ }^{30}$ We again adopt this transformation to address the fact that the distribution of maize-suitable land area across countries is highly skewed, with a minimum value of zero.

${ }^{31}$ Ideally, we would be able to follow the approach taken by Chen and Kung (2016), and assign the post-introduction indicator to be equal to one in the period when maize is first observed being adopted. However, as we discussed above in Section 3.1, the historical record is quite sparse, meaning we do not observe the exact date at which maize was first adopted in any country in Africa. As such, we instead follow the approach of Nunn and Qian (2011) and assume maize is introduced to all countries during the same period.
}

As we noted above, in order for $\hat{\beta}$ to be a credible estimate of the causal effect of the introduction of maize, there can be no other countryspecific factors related to the introduction of maize driving differences in population density or slave exports over time. However, this assumption need not hold necessarily; indeed the results of previous studies suggest that it may be violated because of time-varying factors related to our sources of identifying variation: European contact, and climatic conditions. For example, the work of Whatley (2018) indicates that the guns-for-slave cycle was an important driver slave supply during the slave trades. This means that our estimates could be capturing the effects of other time-varying aspects of European contact, such as the sale of firearms, that may have affected both population density and slave exports. Similarly, recent research by Fenske and Kala (2015) and Boxell (2018) show that increased temperatures and rainfall are associated with reductions in slave exports, respectively. This means that our estimates could also be capturing the effects of weather and seasons. ${ }^{32}$ Hence, in our baseline analysis, we supplement equation (9) with additional controls, given by $X_{i t}$, to ensure that our estimates are not being driven by time-varying aspects of European contact or climatic conditions. ${ }^{33}$ Specifically, we supplement our baseline regression with the natural log of average distance to an ice-free coast, the natural $\log$ of one plus the fraction of land that is within $100 \mathrm{~km}$ of an icefree coast and region indicators for north, west, east, south and central Africa, all interacted with time fixed effects, to control for time-varying differences in European contact given that we do not observe European contact directly. We add the natural logs of two key determinants of climate, distance to the equator and elevation, interacted with time fixed effects to control for the effects of time-varying differences in climatic conditions.

\section{Results}

\subsection{The Crosby-Curtin hypothesis}

Table 3 reports estimates from three specifications based on equation (9) that we use to test the Crosby-Curtin hypothesis. Each panel of the table reports estimates for a different part of the hypothesis: Panel A reports estimates for population density, while Panel B reports estimates for slave exports. The first specification, reported in column (1) of each panel, includes time and country fixed effects. This specification controls for time-invariant cross-country differences, such as geography, and continent wide trends, such as technological change, that may have affected the introduction and adoption of maize. The second specification, reported in column (2), adds the natural log of average distance to an ice-free coast, the natural log of one plus the fraction of land that is within $100 \mathrm{~km}$ of an ice-free coast and region indicators for north, west, east, south and central Africa, all interacted with time fixed effects to account for differential trends in European contact. In our preferred specification, reported in column (3), we add the natural logs of two key determinants of climate, distance to the equator and elevation, interacted with time fixed effects to account for the possibility

\footnotetext{
${ }^{32}$ It is important to note that the results reported by Fenske and Kala (2015) and Boxell (2018) suggests that our estimates would be downward biased, at least for slave exports. For example, Boxell (2018) finds that increased rainfall is associated with reductions in slave exports. Given that maize requires a minimal level of moisture to grow (Miracle, 1966; McCann, 2005), a rainier climate would increase the likelihood of adoption. As such, our estimates would understate the true effects of the introduction of maize on slave exports. Similarly, Fenske and Kala (2015) find that increased temperatures are associated with reductions in slave exports. Maize also grows better at warmer temperatures (Miracle, 1966; McCann, 2005) provided they are not extreme, meaning our estimates likely understate the true effect of the introduction of maize on slave exports.

${ }^{33}$ We examine the possibility our results are capturing the effects of other time-varying factors further in Section 4.2.
} 
Table 3

The Crosby-Curtin hypothesis: Baseline estimates.

\begin{tabular}{llll}
\hline & $(1)$ & $(2)$ & $(3)$ \\
\hline \multicolumn{2}{l}{ Panel A: Population Density } & & \\
\hline Maize $\times$ Post & $0.026^{a}$ & $0.024^{a}$ & $0.025^{a}$ \\
& $(0.009)$ & $(0.008)$ & $(0.007)$ \\
& {$[0.009]$} & {$[0.007]$} & {$[0.007]$} \\
European Contact & & $\mathrm{X}$ & $\mathrm{X}$ \\
Climate & & & $\mathrm{X}$ \\
Observations & 588 & 588 & 588 \\
Adjusted $R^{2}$ & 0.84 & 0.92 & 0.92 \\
Panel B: Slave Exports & & & \\
\hline Maize $\times$ Post & $0.017^{a}$ & $0.022^{a}$ & $0.024^{a}$ \\
& $(0.006)$ & $(0.007)$ & $0.008)$ \\
European Contact & {$[0.006]$} & {$[0.007]$} & {$[0.007]$} \\
Climate & & $\mathrm{X}$ & $\mathrm{X}$ \\
Observations & 245 & 245 & 245 \\
Adjusted $R^{2}$ & 0.20 & 0.40 & 0.41 \\
\hline
\end{tabular}

Notes: Table reports estimates of the effect of maize on population density and slave exports. Panel A reports estimates from OLS regressions of the natural log of population density (persons $/ \mathrm{km}^{2}$ ) on the natural $\log$ of one plus maize suitable land area interacted with a post introduction indicator and other controls. Panel B reports estimates from OLS regressions of the natural log of one plus slave exports (persons exported $/ \mathrm{km}^{2}$ ) on the natural $\log$ of one plus maize suitable land area interacted with a post introduction indicator and other controls. In all cases, each set of control variables is interacted with a full set of year fixed effects. In all specifications, the postintroduction indicator period takes the value 1 for the post 1600 period. All regressions include year fixed effects and country fixed effects. Standard errors clustered by country are reported in round parentheses. Conley (1999) standard errors are reported in square parentheses. ${ }^{a},{ }^{b}$, and ${ }^{c}$ denote significance at the 1,5 and 10 percent levels, respectively.

of differential climate trends across countries. Finally, the table reports two sets of standard error estimates. The first, reported in round parentheses, are clustered by country. The second set, reported in square parentheses, correct for spatial autocorrelation using the approach of Conley (1999) assuming spatial dependence for observations less than $5^{\circ}$ apart. $^{34}$

Panel A of Table 3 reports estimates of the effect of the introduction of maize on population density. These estimates reveal that maize significantly increased population density in countries suitable for its cultivation. For example, the estimate reported in column (1) indicates that a 1 percent increase in the area of land suitable for growing maize is associated with a 0.026 percent increase in population density on average. The estimates reported in columns (2)-(3) show that this effect is robust to allowing for differential trends in European contact and climate across countries; controlling for these trends has little effect on our estimates. Our preferred estimate, reported in column (3), indicates that a 1 percent increase in maize suitable land increased population density by 0.025 percent. Moreover, this effect is statistically significant at conventional levels regardless of whether we cluster standard errors by country, or use Conley (1999) standard errors to correct for spatial correlation. Indeed, our choice of standard errors has little effect on inference; the estimated standard errors from both approaches are nearly identical.

Panel B of Table 3 reports estimates of the effect of the introduction of maize on slave exports. These estimates suggest that maize led to a significant increase in slavery; for example, the estimate reported in column (1) indicates that a 1 percent increase in maize suitable land area is associated with a 0.017 percent increase in slave exports on average. This estimate is quite robust; after controlling for differential trends in European contact and climate, our preferred estimate, reported in column (3), indicates that a 1 percent increase in maize suitable land is

\footnotetext{
${ }^{34}$ We also explored adopting $1^{\circ}, 10^{\circ}$ and $15^{\circ}$ cutoffs, but doing so had little effect on inference. As such they are not reported for the sake of brevity.
}

associated with a 0.024 percent increase in slave exports on average. As with the population estimates presented in Panel A, these effects are significant regardless of whether standard errors are clustered by country or corrected for spatial correlation using the approach of Conley (1999). As such, we only report standard errors clustered by country in subsequent tables.

While the estimates reported in Table 3 provide qualitative support for the Crosby-Curtin Hypothesis, it remains to be seen if the introduction of maize led to economically meaningful changes in outcomes. To this end, we perform two simple calculations to get a better sense of the magnitude of each effect.

First, we determine how maize affected population growth in the average country in Africa. We obtain the population growth attributable to maize by multiplying the benchmark estimate reported in column (3) of Panel A (0.025) by the mean level of our measure of maize suitable land (8.31). This calculation indicates that maize increased the population density of the average country by 21 percent $(0.025 \times 8.31=0.21)$. Based on our data, in 1600 the average country had a population density of 3.45 people $/ \mathrm{km}^{2}$, and in 1900 the average country had a population density of 6.74 people $/ \mathrm{km}^{2}$. These numbers suggest that the population of the average country grew by $95 \%((6.74 / 3.45)-1=0.95)$. Hence, close to $22 \%(0.21 / 0.95=0.22)$ of the population growth in the average country can be attributed to the effects of maize. This suggests that maize had a larger effect on population growth in Africa than in other parts of the world, although in the same order of magnitude; Chen and Kung (2016) find that maize increased population growth in China by $19 \%$ following its introduction. ${ }^{35}$

Second, we determine how maize affected slave exports from the average country at the height of the slave trades. As with our calculation for population growth, we obtain the increase in slave exports

\footnotetext{
35 Our estimates also suggest that maize had similar effects on population growth as the white potato; as shown by Nunn and Qian (2011), the introduction of the white potato explains $26 \%$ of the Old World population growth over the period 1700-1900.
} 
Table 4

The effects of other new world crops.

\begin{tabular}{|c|c|c|c|c|c|}
\hline & (1) & $(2)$ & (3) & (4) & (5) \\
\hline \multicolumn{6}{|c|}{ Panel A: Population Density } \\
\hline Maize $\times$ Post & $\begin{array}{l}0.025^{a} \\
(0.007)\end{array}$ & $\begin{array}{l}0.022^{a} \\
(0.006)\end{array}$ & $\begin{array}{l}0.017^{a} \\
(0.005)\end{array}$ & $\begin{array}{l}0.024^{a} \\
(0.007)\end{array}$ & $\begin{array}{l}0.019^{a} \\
(0.005)\end{array}$ \\
\hline Cassava $\times$ Post & & $\begin{array}{l}0.010 \\
(0.009)\end{array}$ & & & $\begin{array}{l}0.012 \\
(0.009)\end{array}$ \\
\hline White Potato $\times$ Post & & & $\begin{array}{l}0.025^{a} \\
(0.009)\end{array}$ & & $\begin{array}{l}0.027^{a} \\
(0.009)\end{array}$ \\
\hline Sweet Potato $\times$ Post & & & & $\begin{array}{l}0.004 \\
(0.013)\end{array}$ & $\begin{array}{l}-0.024 \\
(0.016)\end{array}$ \\
\hline Observations & 588 & 588 & 588 & 588 & 588 \\
\hline Adjusted $R^{2}$ & 0.92 & 0.92 & 0.93 & 0.92 & 0.93 \\
\hline \multicolumn{6}{|l|}{ Panel B: Slave Exports } \\
\hline Maize $\times$ Post & $\begin{array}{l}0.024^{a} \\
(0.008)\end{array}$ & $\begin{array}{l}0.021^{b} \\
(0.009)\end{array}$ & $\begin{array}{l}0.023^{a} \\
(0.009)\end{array}$ & $\begin{array}{l}0.022^{a} \\
(0.009)\end{array}$ & $\begin{array}{l}0.022^{a} \\
(0.009)\end{array}$ \\
\hline Cassava $\times$ Post & & $\begin{array}{l}0.012^{a} \\
(0.006)\end{array}$ & & & $\begin{array}{l}0.021^{a} \\
(0.009)\end{array}$ \\
\hline White Potato $\times$ Post & & & $\begin{array}{l}0.004 \\
(0.006)\end{array}$ & & $\begin{array}{l}-0.001 \\
(0.006)\end{array}$ \\
\hline Sweet Potato $\times$ Post & & & & $\begin{array}{l}0.007 \\
(0.007)\end{array}$ & $\begin{array}{l}-0.016^{c} \\
(0.008)\end{array}$ \\
\hline Observations & 245 & 245 & 245 & 245 & 245 \\
\hline Adjusted $R^{2}$ & 0.41 & 0.42 & 0.41 & 0.41 & 0.42 \\
\hline
\end{tabular}

Notes: Table reports estimates of the effect of various New World crops on population density, and slave exports. In Panel A, the dependent variable is the natural log of population density (in persons $/ \mathrm{km}^{2}$ ). In Panel $\mathrm{B}$, the dependent variable is the natural $\log$ of one plus slave exports (in persons $/ \mathrm{km}^{2}$ ). For maize, the post-introduction indicator period takes the value 1 for the period from 1600 onward and is 0 otherwise, while for cassava, white potato, and sweet potato, the post-introduction indicator takes the value 1 for the period from 1800 onward and is 0 otherwise. All regressions include year fixed effects, country fixed effects, and controls for differential trends in European contact and climate. Standard errors clustered by country are reported in parentheses. ${ }^{a},{ }^{b}$, and ${ }^{c}$ denote significance at the 1 percent, 5 percent and 10 percent levels, respectively.

attributable to maize by multiplying our benchmark estimate from column (3) of Panel B (0.024) by the mean level of our measure of maize suitable land (8.31). This indicates that slave exports from the average country increased by close to 20 percent $(0.024 \times 8.31=0.20)$ due to maize. Based on our data, the average country exported 0.10 people $/ \mathrm{km}^{2}$ in the $1600 \mathrm{~s}$, and 0.42 people $/ \mathrm{km}^{2}$ in the $1700 \mathrm{~s}$. This means that slave exports from the average country grew by approximately 320 percent $((0.42 / 0.10)-1=3.20)$ at the height of the slave trades. Accordingly, over 6 percent $(0.20 / 3.20=0.06)$ of the total increase in slave exports at this time can be attributed to the effects of maize.

Altogether, the estimates reported in Table 3 are broadly supportive of the Crosby-Curtin Hypothesis. It is worth noting that, despite the large differences in maize's total effect on population growth and slave exports implied by our calculations, our coefficient estimates indicate that maize had very similar effects on population density and slave exports. ${ }^{36}$ This means that maize had little to no effect on the intensity of slave exports (the number of slaves exported as a fraction of the population), suggesting that the crop effectively functioned as a supply-side shock that simply amplified the magnitude of the slave trade.

\subsection{Alternative explanations}

The estimates presented above suggest that the introduction of maize significantly increased population levels and slave exports in affected African countries. We now turn to examine whether our base-

\footnotetext{
${ }^{36}$ Indeed, the estimates reported in column (3) of both panels of the table are not statistically different from each other.
}

line results are capturing the effects of other factors. ${ }^{37}$ First, we examine whether our estimates are capturing the effects of other New World crops that were introduced into Africa during our period of study. Second, we examine whether our estimates are robust to controlling for the effects of other factors that have been identified as important determinants of either population density or slave exports in Africa.

To check if our estimates are capturing the effects of the introduction of other New World crops, we supplement our main estimating equation with measures analogous to $\left[\right.$ Maize $_{i} \times$ Post $\left._{t}\right]$ for cassava, the sweet potato and the white potato. As with $\left[\right.$ Maize $_{i} \times$ Post $\left._{t}\right]$, we construct these variables by interacting the natural log of one plus the land area suitable for the growth of each crop with a post-introduction indicator. However, unlike the case of maize where the indicator is equal to one for the period from 1600 onward, for the three other crops, the indicator is equal to one for the period from 1800 onward. This ensures that we are consistent with the available evidence as to the timing of their introductions; as we discussed above in Section 3.1, cassava, sweet potatoes and white potatoes were not widely adopted as staple crops in Africa until the 19th century.

These results are presented in the two panels of Table 4. For convenience, column (1) of each panel reports the baseline estimates previously reported in column (3) of Table 3. Column (2)-(4) add measures to capture the introduction of cassava, white potatoes, and sweet potatoes, respectively. Finally, column (5) controls for the introduction of all four New World crops simultaneously. Each specification includes country and year fixed effects as well as controls for differential trends

\footnotetext{
${ }^{37}$ In the online appendix, we present additional results documenting the robustness of our baseline results to our definition of treatment, particularly the timing of maize's introduction and our measure of agricultural productivity, as well as to our use of the transformation $\ln (1+x)$ to address skewness in the distributions of slave exports and maize suitable land area, and accounting for dynamics in slave exports and population density.
} 
Table 5

The effects of maize: Alternative explanations.

\begin{tabular}{|c|c|c|c|c|c|c|c|}
\hline & (1) & (2) & (3) & (4) & (5) & (6) & (7) \\
\hline \multicolumn{8}{|c|}{ Panel A: Population Density } \\
\hline Maize $\times$ Post & $\begin{array}{l}0.025^{a} \\
(0.007)\end{array}$ & $\begin{array}{l}0.040^{a} \\
(0.015)\end{array}$ & $\begin{array}{l}0.023^{a} \\
(0.009)\end{array}$ & $\begin{array}{l}0.015^{a} \\
(0.005)\end{array}$ & $\begin{array}{l}0.021^{a} \\
(0.006)\end{array}$ & $\begin{array}{l}0.026^{a} \\
(0.008)\end{array}$ & $\begin{array}{l}0.023^{c} \\
(0.014)\end{array}$ \\
\hline Baseline Controls & $\mathrm{x}$ & $\mathrm{x}$ & $\mathrm{x}$ & $\mathrm{x}$ & $\mathrm{x}$ & $\mathrm{x}$ & $\mathrm{x}$ \\
\hline Old World Crops & & $\mathrm{x}$ & & & & & $\mathrm{x}$ \\
\hline Ruggedness & & & $\mathrm{x}$ & & & & $\mathrm{x}$ \\
\hline Market Distance & & & & $\mathrm{x}$ & & & $\mathrm{x}$ \\
\hline Tsetse Suit. Index & & & & & $\mathrm{x}$ & & $\mathrm{x}$ \\
\hline Malaria Index & & & & & & $\mathrm{x}$ & $\mathrm{x}$ \\
\hline Observations & 588 & 588 & 588 & 588 & 588 & 588 & 588 \\
\hline Adjusted $R^{2}$ & 0.92 & 0.93 & 0.93 & 0.94 & 0.93 & 0.92 & 0.94 \\
\hline \multicolumn{8}{|c|}{ Panel B: Slave Exports } \\
\hline Maize $\times$ Post & $\begin{array}{l}0.024^{a} \\
(0.008)\end{array}$ & $\begin{array}{l}0.032^{a} \\
(0.014)\end{array}$ & $\begin{array}{l}0.025^{a} \\
(0.009)\end{array}$ & $\begin{array}{l}0.024^{a} \\
(0.008)\end{array}$ & $\begin{array}{l}0.024^{a} \\
(0.009)\end{array}$ & $\begin{array}{l}0.022^{a} \\
(0.008)\end{array}$ & $\begin{array}{l}0.032^{a} \\
(0.014)\end{array}$ \\
\hline Baseline Controls & $\mathrm{x}$ & $\mathrm{x}$ & $\mathrm{x}$ & $\mathrm{x}$ & $\mathrm{x}$ & $\mathrm{x}$ & $\mathrm{x}$ \\
\hline Old Staple Crops & & $\mathrm{x}$ & & & & & $\mathrm{x}$ \\
\hline Ruggedness & & & $\mathrm{x}$ & & & & $\mathrm{x}$ \\
\hline Market Distance & & & & $\mathrm{x}$ & & & $\mathrm{x}$ \\
\hline Tsetse Suit. Index & & & & & $\mathrm{x}$ & & $\mathrm{x}$ \\
\hline Malaria Index & & & & & & $\mathrm{x}$ & $\mathrm{x}$ \\
\hline Observations & 245 & 245 & 245 & 245 & 245 & 245 & 245 \\
\hline Adjusted $R^{2}$ & 0.41 & 0.41 & 0.41 & 0.44 & 0.40 & 0.41 & 0.42 \\
\hline
\end{tabular}

Notes: Table reports estimates of the effect of maize on population density and slave exports. Panel A reports estimates from OLS regressions of the natural $\log$ of population density (in persons $/ \mathrm{km}^{2}$ ) on the natural $\log$ of one plus maize suitable land area interacted with a post introduction indicator and other controls. Panel B reports estimates from OLS regressions of the natural log of one plus slave exports (in persons $/ \mathrm{km}^{2}$ ) on the natural log of one plus maize suitable land area interacted with a post introduction indicator and other controls. In all specifications, the post-introduction indicator period takes the value 1 for the post- 1600 period and is 0 otherwise. All regressions include year fixed effects and country fixed effects, and baseline controls for differential trends in European contact and climate. All control variables are interacted with a full set of year fixed effects. Standard errors clustered by country are reported in parentheses. ${ }^{a},{ }^{b}$, and ${ }^{c}$ denote significance at the 1 percent, 5 percent and 10 percent levels, respectively.

in European contact and climate. Standard errors clustered by country are reported in parentheses.

The estimates reported in Table 4 suggest that our baseline results are not simply capturing the effects of the introduction of other New World crops. For the most part, the estimated effects of maize change little once we control for the other crops. The key exception to this is the effect of the white potato on population density; as the estimates reported in columns (3) and (5) of panel A show, separately controlling for the effects of the white potato leads to modest decreases in the estimated effect of maize. This suggests that our baseline results for population density are, in part, capturing the effects of the introduction of the white potato at the end of the 1800s. This timing explains the absence of a corresponding change in slave exports; by the time of the potato's introduction into Africa, the Trans-Atlantic slave trade - the largest of the four slave trades - was ending.

As a final robustness check, we examine if our results are capturing the effects of other factors that have been identified as important determinants of either population density or slave exports. These results are reported in Table 5. In panel A, the dependent variable is the natural $\log$ of population density (in persons $/ \mathrm{km}^{2}$ ). In panel $\mathrm{B}$, the dependent variable is the natural $\log$ of one plus slave exports (in persons $/ \mathrm{km}^{2}$ ). For convenience, column (1) in each panel reports the baseline estimates previously reported in column (3) of the corresponding panel of Table 3. Columns (2)-(6) in each report estimates from specifications that include controls for an alternative explanation for the effects of maize. The final column controls for all of these determinants simultaneously. All errors are clustered by country.

We begin by examining the possibility that our results are not capturing the effects of maize, but rather the effects of preexisting population trends created by cross-country differences in the suitability of land for growing sorghum and pearl millet, the two primary staple crops in Africa before the introduction of maize. As such, in the specification reported in column (2) we include the natural log of both one plus sorghum suitable land area and one plus pearl millet suitable land area, both interacted with time fixed effects. As the estimate reported in column (2) of Panel A shows, controlling for these crops leads to an increase in the estimated effect of maize on population density, suggesting that our baseline estimate may underestimate the true effect of maize. The same is true for slave exports; the estimate reported in column (2) of Panel B shows that controlling for these crops also leads to an increase in the estimated effect of maize.

In columns (3) and (4), we investigate whether our estimates are capturing the effects of differential trends in factors that would affect the demand for and supply of slaves. The supply of slave exports depended, in part, on the ruggedness of terrain; ruggedness reduced slavery by making raids more difficult (Nunn and Puga, 2012). Hence, in column (3), we include the natural log of average ruggedness interacted with time-period fixed effects to account for differential trends in the ease of raiding across countries. Slaves were often exported to the nearest source of demand, meaning that our estimates could be capturing the effects of differential demand shocks across destination markets. To account for this, in column (4), we include the log of distance to the nearest market for each of the four slave trades interacted with time-period fixed effects. ${ }^{38}$ As the estimates reported in columns (3) and (4) show, controlling for these factors has little effect on results for slave exports. The estimate reported in column (4) of Panel A, indicates that controlling for distance to market leads to a modest decrease in the estimated effect of maize on population density. This may mean our baseline results potentially reflect the effects of other trading relationships not captured by our measures of European contact. However, this decrease does not appear to be robust; when we simultaneously control for other alternative explanations in column (7), the decrease disappears.

\footnotetext{
38 The data on distances comes from Nunn and Puga (2012).
} 
Table 6

The effects of maize on economic growth and conflict.

\begin{tabular}{|c|c|c|c|c|c|c|c|c|c|}
\hline & \multicolumn{3}{|c|}{ Economic Growth } & \multicolumn{3}{|c|}{ Any Conflict } & \multicolumn{3}{|c|}{ Number of Conflicts } \\
\hline & (1) & (2) & (3) & (4) & (5) & (6) & (7) & (8) & (9) \\
\hline Maize $\times$ Post & $\begin{array}{l}-0.001 \\
(0.001)\end{array}$ & $\begin{array}{l}-0.001 \\
(0.001)\end{array}$ & $\begin{array}{l}-0.001 \\
(0.001)\end{array}$ & $\begin{array}{l}0.021 \\
(0.018)\end{array}$ & $\begin{array}{l}0.076^{a} \\
(0.037)\end{array}$ & $\begin{array}{l}0.055^{c} \\
(0.031)\end{array}$ & $\begin{array}{l}0.072^{a} \\
(0.029)\end{array}$ & $\begin{array}{l}0.101 \\
(0.061)\end{array}$ & $\begin{array}{l}0.064 \\
(0.056)\end{array}$ \\
\hline ln(Slave Exports) & & & $\begin{array}{l}0.000 \\
(0.000)\end{array}$ & & & $\begin{array}{l}0.049^{a} \\
(0.014)\end{array}$ & & & $\begin{array}{l}0.083^{a} \\
(0.029)\end{array}$ \\
\hline Baseline Controls & $\mathrm{X}$ & $\mathrm{X}$ & $\mathrm{X}$ & $\mathrm{X}$ & $\mathrm{X}$ & $\mathrm{X}$ & $\mathrm{X}$ & $\mathrm{X}$ & $\mathrm{X}$ \\
\hline Alt. Explan. & & $\mathrm{X}$ & $\mathrm{X}$ & & $\mathrm{X}$ & $\mathrm{X}$ & & $\mathrm{X}$ & $\mathrm{X}$ \\
\hline Observations & 588 & 588 & 441 & 245 & 245 & 245 & 245 & 245 & 245 \\
\hline Adjusted $R^{2}$ & 0.08 & 0.12 & 0.08 & 0.26 & 0.34 & 0.38 & 0.39 & 0.43 & 0.46 \\
\hline
\end{tabular}

Notes: Table reports estimates of the effect of maize on economic growth and conflict. In columns (1) to (3) the dependent variable is the urbanization rate. In columns (4) to (6), the dependent variable is an indicator equal to one if any conflicts occurred during century $t$. In columns (7) to (9) the dependent variable is the natural $\log$ of one plus the number of conflicts that occurred during century $t$. In all specifications, the post-introduction indicator period takes the value 1 for the post-1600 period and is 0 otherwise. All regressions include year fixed effects and country fixed effects, and baseline controls for differential trends in European contact and climate. All control variables are interacted with a full set of year fixed effects. Standard errors clustered by country are reported in parentheses. ${ }^{a},{ }^{b}$, and ${ }^{c}$ denote significance at the 1 percent, 5 percent and 10 percent levels, respectively.

Next we investigate whether our estimates are capturing the effects of differences in disease environment. As indicated by Acemoglu et al. (2001), malaria was a key determinant of European contact in much of the world; given that maize was introduced by Europeans, it is possible that our results are capturing differential trends in European contact due to differences in the prevalence of malaria. Furthermore, recent research by Alsan (2015) has shown that the Tsetse fly inhibited agriculture and affected both population growth and slavery in much of Africa. We control for these factors by including the malaria ecology index of Kiszewski et al. (2004) and the Tsetse Suitability Index of Alsan (2015), both interacted with time period fixed effects (columns (5) and (6) respectively). Controlling for these factors does not significantly change our baseline results. Allowing for differential trends based on Tsetse suitability decreases the estimated effect of maize on population density, but the effect is still significant and is not statistically different than our baseline estimate.

Finally, in column (8) we control for all of these factors simultaneously. Doing so does not significantly change the estimated effects of maize on either population density or slave exports, further suggesting that our baseline estimates are not driven by other important factors that shaped Africa's history.

\subsection{Maize, economic growth, and conflict}

Altogether, the estimates presented above suggest that the introduction of maize affected both population density and slave exports in a manner consistent with the Crosby-Curtin Hypothesis. What remains to be seen is if maize had effects beyond those envisioned by either Curtin or Crosby. Recent research has shown that the introduction of the white potato and the sweet potato to the Old World during the Columbian Exchange increased economic growth (Nunn and Qian, 2011) and reduced conflict (Jia, 2014; Iyigun et al., 2015). As such, we investigate if maize affected either channel; if maize had similar effects in Africa, it would suggest that the negative effects of slavery (Nunn, 2008; Nunn and Wantchekon, 2011) may have been at least partially offset by the introduction of maize.

We identify the effects of the introduction of maize on both economic growth and conflict by again exploiting the research design that we outlined above in Section 3. Hence, we again employ equation (9) to estimate the effects of maize, but for specifications using measures of either economic growth or conflict as the dependent variable.

Estimating the effect of maize on economic growth is complicated by the fact that reliable GDP estimates are not available for Africa throughout our period of study. To deal with this issue, we follow the approach taken by both Nunn and Qian (2011) and Chen and Kung (2016) and use urbanization rates as a proxy for economic growth. ${ }^{39}$ Our urbanization data comes from Nunn and Qian (2011), and measures the fraction of total population located in cities with more the 40,000 inhabitants. ${ }^{40}$

Our data on conflict comes from Brecke (1999), who constructed a database of major historical conflicts (defined as at least 32 battle deaths) over the period 1400-1900. ${ }^{41}$ We use this data to construct two measures of conflict in each country by century. First, we construct an indicator variable equal to one if any conflicts occurred in country $j$ during century $t$. This allows us to examine if the introduction of maize had an effect on the likelihood of conflict. Second, we determine the total number of conflicts in country $j$ that occurred during century $t$. This allows us to examine if maize had any effect on the number of conflicts that occurred in Africa.

Our estimates of the effects of maize on economic growth are reported in columns (1)-(3) of Table 6. In all three cases, the dependent variable is the urbanization rate. Column (1) includes controls corresponding to the baseline estimates reported in Table 3, while column (2) also include controls for the additional explanations examined in Table 5. Finally, column (3) adds the natural log of one plus total slave exports. ${ }^{42}$ In all cases, standard errors clustered by country are reported in parentheses.

The estimates presented in the columns (1) and (2) of Table 6 suggest that the maize had no meaningful effect on urbanization rates, suggesting that maize failed to stimulate economic growth in Africa. This result stands in sharp contrast to those presented by Nunn and Qian (2011), who suggest that the introduction of the potato stimulated economic growth in much of the Old World. Instead, our results mirror those of Chen and Kung (2016), who find that maize failed to increase economic growth in China. One possible explanation for this is that the effects of maize on economic growth are being confounded by the effects of the slave trades; however, as the estimates presented in column (3) show, controlling for total slave exports has little effect on the estimated coefficient for maize. As such, these results provide further evidence that agricultural productivity shocks alone are not sufficient to generate sustained economic growth.

Our estimates of the effects of maize on conflict are presented in columns (4)-(9) of Table 6. In columns (4)-(6), the dependent variable

\footnotetext{
${ }^{39}$ As shown by Acemoglu et al. (2002), there is a strong correlation between urbanization and income per capita.

40 The data from Nunn and Qian (2011) is constructed from Chandler (1987), Bairoch (1988) and Modelski (2003). For further details, see Nunn and Qian (2011).

41 Fenske and Kala (2017) employ this data to study how the suppression of the slave trade in 1807 affected conflict in Africa.

42 This reduces our sample size; because we do not observe total slave exports in 1750, 1850 and 1900, we are forced to drop these observations.
} 
is the conflict indicator, meaning the estimate reflects the effects of maize on the likelihood any major conflict occurred. In columns (7)-(9), the dependent variable is the natural log of one plus the number of conflicts. In this case the each estimate captures the effect of maize on the number of major conflicts. In all cases, standard errors clustered by country are again reported in parentheses.

While the estimates reported in columns (1)-(3) suggest that maize had little effect on urbanization, the estimates reported in columns (4)-(9) suggest that maize may have increased conflict. For example, the estimate reported in column (7) indicates that the introduction of maize led to a $7.6 \%$ increase in the likelihood of conflict within a country. Similarly, the estimate reported in column (8) indicates that the introduction of maize is associated with a $10.1 \%$ increase in the number of conflicts within a country, although this effect is not statistical significant at conventional levels. These results are in sharp contrast to those of Jia (2014) or Iyigun et al. (2015) who find evidence that New World crops reduced conflict when introduced in China and Europe. This is likely due to the different institutions in place in Africa; as the estimates reported in columns (6) and (9) show, the increases in conflict created by the introduction of maize appear to be largely driven by the slave trades.

Altogether, the results presented in Table 6 suggest that the introduction of maize did not offset the negative effects of the slave trades by increasing economic growth or reducing conflict. Instead our findings suggest that the introduction of maize may have increased conflict by increasing the size of the slave trades.

\section{Conclusion}

In this paper, we examine how the introduction of maize, a New World crop, affected population levels and slave exports in precolonial Africa. Our analysis is motivated by a hypothesis implicit in observations made by the historians Alfred Crosby (1972) and Philip Curtin (1969). This hypothesis, which we term the Crosby-Curtin Hypothesis, predicts that the introduction of New World Crops into Africa during the Columbian Exchange increased population levels and slave exports in affected countries.

Our reading of a combination of modern evidence on the productivity of various crops and historical evidence on the spread of New World crops to Africa suggests that maize is the likely source of the effects envisioned by Crosby and Curtin. As such, we exploit cross-country variation in the suitability of maize as a crop and temporal variation arising from the timing of maize's introduction in Africa to test the two parts of the hypothesis. We find robust support for these predictions; we find that the arrival of maize significantly increased population density and slave exports in affected countries. Given that the linkage between agricultural productivity changes, population and slavery are not made explicit by either Crosby or Curtin, we show that these effects can be rationalized with the aid of a simple Malthusian growth model.

We also explore whether the introduction of maize had effects aside from those envisioned by Crosby and Curtin. To this end, we examine whether maize had effects on either economic growth or conflict, and find little evidence that suggests maize affected either channel. As such, our results suggest that the introduction of maize did not allow Africa to escape the Malthusian trap; rather, it appears that the introduction of maize simply contributed to an increase in the magnitude of the slave trades.

\section{Acknowledgements}

We would like to thank the editor, Nathan Nunn, and two anonymous reviewers for helpful comments and suggestions. We have also benefited from feedback from Branko Bošković, Byung-Cheol Kim, David Laband, Runjuan Liu, Arvind Magesan, Barry Scholnick and seminar participants at Georgia State, Georgia Tech, the University of Alberta, CESifo, and the 2014 Canadian Economic Association meet- ings. We would also like to thank Nathan Nunn for sharing his slave export data with us. Support from the Social Sciences and Humanities Research Council of Canada and National Science Foundation Grant no. 1510510 are gratefully acknowledged. Other declarations of interest: None.

\section{Appendix A. Supplementary data}

Supplementary data to this article can be found online at https:// doi.org/10.1016/j.jdeveco.2018.10.008.

\section{References}

Acemoglu, D., Johnson, S., Robinson, J.A., 2001. The colonial origins of comparative development: an empirical investigation. Am. Econ. Rev. 91 (5), 1369-1401.

Acemoglu, D., Johnson, S., Robinson, J.A., 2002. Reversal of fortune: geography and institutions in the making of the modern world income distribution. Q. J. Econ. 117 (4), 1231-1294.

Alpern, S.B., 1992. The European introduction of crops into West Africa in precolonial times. Hist. Afr. 19, 13-43.

Alsan, M., 2015. The effect of the tsetse fly on African development. Am. Econ. Rev. 105 (1), 382-410.

Ashraf, Q., Galor, O., 2011. Dynamics and stagnation in the Malthusian epoch. Am. Econ. Rev. 101 (5), 2003-2041.

Austin, G., 2008. The 'reversal of fortune' thesis and the compression of history: perspectives from African and comparative economic history. J. Int. Dev. 20 (8), 996-1027.

Bairoch, P., 1988. Cities and Economic Development: from the Dawn of History to the Present. University of Chicago Press, Chicago, Illinois.

Bertocchi, G., 2016. The legacies of slavery in and out of Africa. IZA J. Migrat. 5, 1-19.

Bertocchi, G., Dimico, A., 2017. The Long-term Determinants of Female HIV Infection in Africa: the Slave Trade, Polygyny, and Sexual Behavior. Mimeo.

Boxell, L., 2018. Droughts, Conflict, and the African Slave Trade. Mimeo.

Brecke, P., 1999. Violent conflicts $1400 \mathrm{AD}$ to the present in different regions of the world. In: Paper Presented at the Annual Meeting of the Peace Science Society (International).

Chandler, T., 1987. Four Thousand Years of Urban Growth: an Historical Census. The Edwin Mellen Press, Lewiston, New York.

Chen, S., Kung, J.K., 2016. Of maize and men: the effect of a new world crop on population and economic growth in China. J. Econ. Growth 21 (1), 71-99.

Clark, G., 2007. A Farewell to Alms. Princeton University Press.

Conley, T.G., 1999. GMM estimation with cross sectional dependence. J. Econom. 92 (1), 1-45.

Crosby, A.W., 1972. The Columbian Exchange: Biological and Cultural Consequences of 1492. Greenwood Publishing Company, Westport, Connecticut.

Curtin, P.D., 1969. The Atlantic Slave Trade: a Census. The University of Wisconsin Press, Madison, Wisconsin.

Dalton, J.T., Leung, T.C., 2014. Why is polygyny more prevalent in western Africa? An African slave trade perspective. Econ. Dev. Cult. Change 62 (4), 599-632.

Dalton, J.T., Leung, T.C., 2015. Dispersion and distortions in the Trans-Atlantic slave trade. J. Int. Econ. 96 (2), 412-425.

Dalton, J.T., Leung, T.C., 2016. Being Bad by Being Good: Owner and Captain Value-added in the Slave Trade. Mimeo.

Eltis, D., Lewis, F.D., McIntyre, K., 2010. Accounting for the traffic in Africans: transport costs on slaving voyages. J. Econ. Hist. 70 (4), 940-963.

Eltis, D., Lewis, F.D., Richardson, D., 2005. Slave prices, the African slave trade, and productivity in the Caribbean, 1674-1807. Econ. Hist. Rev. 58 (4), 673-700.

Fenske, J., 2013. Does land abundance explain African institutions? Econ. J. 123 (573), 1363-1390.

Fenske, J., Kala, N., 2015. Climate and the slave trade. J. Dev. Econ. 112, 19-32.

Fenske, J., Kala, N., 2017. 1807: economic shocks, conflict and the slave trade. J. Dev. Econ. 126, 66-76.

Gennaioli, N., Rainer, I., 2007. The modern impact of precolonial centralization in Africa. J. Econ. Growth 12 (3), 185-234.

Gershman, B., 2017. Witchcraft Beliefs as a Cultural Legacy of the Atlantic Slave Trade: Evidence from Two Continents. Mimeo.

Gillezeau, R., Whatley, W., 2011. The impact of the Trans-Atlantic slave trade on ethnic stratification in Africa. Am. Econ. Rev.: Pap. Proceed. 101 (3), 571-576.

Hogendorn, J., Gemery, H., 1990-1991. Assessing productivity in precolonial African agriculture and industry 1500-1800. Afr. Econ. Hist. 19, 31-35.

Hopkins, A.G., 1973. An Economic History of West Africa. Columbia University Press, New York, New York.

Hopkins, A.G., 2009. The new economic history of Africa. J. Afr. Hist. 50 (2), 155-177.

IIASA/FAO, 2012. Global Agro-ecological Zones (GAEZ v3.0). IIASA, Laxenburg, Austria and FAO, Rome, Italy.

Iyigun, M., Nunn, N., Qian, N., 2015. Agricultural Productivity and Conflict: Evidence from the Diffusion of Potatoes to the Old World. Mimeo.

Jia, R., 2014. Weather shocks, sweet potatoes and peasant revolts in historical China. Econ. J. 124 (575), 92-118.

Jones, W.O., 1959. Manioc in Africa. Stanford University Press, Stanford, California.

Juhé-Beaulaton, D., 1990. La diffusion du maïs sur les côtes de l'or ed des esclaves aux XVIIe et XVIIIe siécles. Rev. Françias Histoire Outre-mer 77 (287), 177-198. 
Kiszewski, A., Mellinger, A., Speilman, A., Malaney, P., Sachs, S.E., Sachs, J., 2004. A global index of the stability of malaria transmission. Am. J. Trop. Med. Hyg. 70, $486-498$.

Kusimba, C.M., 2004. Archaeology of slavery in East Africa. Afr. Archaeol. Rev. 21 (2), 59-88.

Lagerlof, N., 2008. Supplementary Notes to 'Slavery and Other Property rights.'. Mimeo. Lagerlof, N., 2009. Slavery and other property rights. Rev. Econ. Stud. 76 (1), 319-342.

Lamb, H., Darbyshire, I., Verschuren, D., 2003. Vegetation response to rainfall variation and human impact in central Kenya during the past 1100 years. Holocene 13 (2), 285-292.

Lovejoy, P.E., 2000. Transformations in Slavery: a History of Slavery in Africa, second ed. Cambridge University Press, Cambridge, UK.

McCann, J.C., 2001. Maize and grace: history, corn, and Africa's new landscapes, 1500-1999. Comp. Stud. Soc. Hist. 43 (2), 246-272.

McCann, J.C., 2005. Maize and Grace: Africa's Encounter with a New World Crop, 1500-2000. Harvard University Press, Cambridge, Massachusetts.

McEvedy, C., Jones, R., 1978. Atlas of World Population History. Viking.

Michalopoulos, S., Papaioannou, E., 2013. Pre-colonial ethnic institutions and contemporary African development. Econometrica 81 (1), 113-152.

Mir, C., Zerjal, T., Combes, V., Dumas, F., Madur, D., Bedoya, C., Dreisgacker, S., Franco, J., Grudloyma, P., Hao, P., Hearne, S., Jampatong, C., Laloe, D., Muthamia, Z., Nguyen, T., Prasanna, B., Taba, S., Xie, C., Yunus, M., Zhang, S., Warburton, M., Charcosset, A., 2013. Out of America: tracing the genetic footprints of the global diffusion of maize. Theor. Appl. Genet. 126, 2671-2682.

Miracle, M.P., 1965. The introduction and spread of maize in Africa. J. Afr. Hist. 6 (1), 39-55.

Miracle, M.P., 1966. Maize in Tropical Africa. The University of Wisconsin Press, Madison, Wisconsin.

Modelski, G., 2003. World Cities: 3000 to 2000. Faros, Washington, D.C..
Nunn, N., 2008. The long term effect of Africa's slave trades. Q. J. Econ. 123 (1), 139-176.

Nunn, N., 2014. Chapter 7 - historical development. In: Aghion, P., Durlauf, S.N. (Eds.), Handbook of Economic Growth. Volume 2 of Handbook of Economic Growth, Elsevier, pp. 347-402.

Nunn, N., Puga, D., 2012. Ruggedness: the blessing of bad geography in Africa. Rev. Econ. Stat. 94 (1), 20-36.

Nunn, N., Qian, N., 2010. The Columbian Exchange: a history of disease, food, and ideas. J. Econ. Perspect. 24 (2), 163-188.

Nunn, N., Qian, N., 2011. The potato's contribution to population and urbanization: evidence from a historical experiment. Q. J. Econ. 126 (2), 593-650.

Nunn, N., Wantchekon, L., 2011. The slave trade and the origins of mistrust in Africa. Am. Econ. Rev. 101 (7), 3221-3252.

O'Brien, P.J., 1972. The sweet potato: its origin and dispersal. Am. Anthropol. 74 (3), 342-365.

Purseglove, J.W., 1972. Tropical Crops: Monocotyledons 1. Longman Group Limited, London.

Rönnbäck, K., Theodoridis, D., 2018. African agricultural productivity and the Trans-Atlantic slave trade: evidence from Senegambia in the nineteenth century. Econ. Hist. Rev., https://doi.org/10.1111/ehr.12697.

Stahl, A.B., 1999. The archaeology of global encounters viewed from Banda, Ghana. Afr. Archaeol. Rev. 16 (1), 5-81.

Vansina, J., 1990. Paths in the Rainforests. The University of Wisconsin Press, Madison, Wisconsin.

Whatley, W., 2018. The gun-slave hypothesis and the 18th century British slave trade. Explor. Econ. Hist. 67, 80-104. 